\title{
Research on the Efficiency of Testing a New Adsorbent Material with Cellulose Structure for the Depollution of Waste Water
}

\author{
RALUCA ELENA GINGHINA ${ }^{1 *}$, DIONEZIE BOJIN², TUDOR VIOREL TIGANESCU ${ }^{3}$, \\ NICOLETA PETREA ${ }^{1}$, SIMONA BUNGAU ${ }^{*}$, DANUT-EUGENIU MOSTEANU ${ }^{5}$ \\ ${ }^{1}$ Scientific Research Center for CBRN Defense and Ecology, 225 Oltenitei Road, 041309 Bucharest, Romania \\ ${ }^{2}$ Politehnica University of Bucharest, 313 Splaiul Independentei, 060042 Bucharest, Romania \\ ${ }^{3}$ Military Equipment and Technologies Research Agency, 16 Aeroportului Str., 077025 Clinceni, Romania \\ ${ }^{4}$ University of Oradea, Faculty of Medicine and Pharmacy, 29 N. Jiga Str., 410028 Oradea, Romania \\ ${ }^{5}$ Land Forces Academy Nicolae Balcescu, 3-5 Revolutiei Str., 550170 Sibiu, Romania
}

\begin{abstract}
The global concern in wastewater recycling technologies has grown steadily since the early 1990s and is gaining more and more interest due to the increase in water supply needs. This growing need affects many global regions and leads to an increase in the strictness of environmental regulation, both in developing and developed countries. Many countries, cities and local governments are trying to recycle wastewater as a potential source of water for various uses, especially non-potable uses, such as land use, water for toilets and industrial processes. Analysts and statisticians around the world are trying to provide a perspective on an industry that is poised to see significant developments in the next decade. The researches summarize the experimental tests carried out using a new cellulosic adsorbent material to purify the wastewater resulted from the industrial processes for leather manufacturing. The study highlights the influence of the $\mathrm{pH}$ used for the wastewater depollution. The tracked and measured parameters include the $\mathrm{pH}$, chemical oxygen demand, biochemical oxygen demand, total suspended solids, ammoniac nitrogen, organic compounds extractable in organic solvents and the solid residue adsorbed by the material. The obtained values were discussed in concordance with the national legislation for wastewater treatment and the levels accepted for releasing the used water in the surface waters.
\end{abstract}

Keywords: wastewater treatment, cellulosic adsorbent material, SEM/EDX, metal oxides

\section{Introduction}

The threats associated with the global water shortage are becoming more and more current news, as a result of the continuous increase of agricultural production [1,2], the expansion of urban borders, the production of large industrial water-consuming installations and the increased sensitivity for environmental needs, lead to an increased demand for water. Another worrying factor is the increased pollution of the environment, and implicitly of water, with excessive numbers and quantities of substances / chemicals / metal ions also coming from agriculture, industry, poor household waste management [3-5], corrosion [6-8], etc. Constraints on water supply are further accentuated by the presence of drought on large areas of the globe, which has led to economic losses of tens of billions of dollars in the agricultural sector alone. In response to these concerns, authorities around the world, responsible for water management, are constantly seeking creative solutions to address these shortcomings [9-15].

\footnotetext{
*email: ginghinaraluca@gmail.com; simonabungau@gmail.com
} 
Recently, on the water supply market, there has been a considerable differentiation of the procedures for the treatment of drinking water out of the non-potable water [16]. Drinking water must meet rigorous public health requirements to ensure that water-related diseases and harmful levels of pollutants are not transmitted to humans. In contrast, agricultural irrigation, urban irrigation, washing of toilets and, in some cases, the water released into the environment doesn't necessarily need to meet such strict treatment requirements. This differentiation allowed the water managers to implement the recycling and reuse of wastewater, where the water is depolluted to the minimum standards necessary to comply with the values provided by the environmental legislation. In an annual report from the European Commission, it is estimated that by 2030 the global demand for water, that cannot be met, will increase to about 3,000 cubic kilometres of water $[17,18]$.

A proliferation of wastewater recycling methods in the upcoming decades could support a significant reduction of the water deficit problem. The idea of water re-potabilization in wastewater treatment plants and the direct reintroduction into a water supply system, had an unforeseen impact on the population, nicknaming the process toilet to tap, being evaluated by yuck factor, in translation a sense of disgust generated by this idea. As consumers begin to accept the technological solutions that can properly clean the water, purifying it, the use of recycled water will become more widespread [19].

\section{Materials and methods}

Preparation of a new nanostructured adsorbent material with cellulose matrix

The scientists' interests in the production of cellulose matrix materials, such as cellulose gels, cellulose composites, cellulose derivatives, functionalized cellulose and nanocrystalline cellulose, with applicability in wastewater treatment, has been manifested since the 2000s. The functionalization of metal oxide matrices represents an intensely researched sub-domain, in order to achieve adsorption selectivity as efficiently as possible, for various categories of substances, or specific to industries $[20,21]$.

The experimental work aims to develop a new cellulose matrix material, functionalized with metallic oxides of $\mathrm{Fe}$ and $\mathrm{Al}$, for later use in the treatment of wastewater from various industries. The preparation of the material consisted in three steps: preparation of the cellulose matrix, preparation of the oxide mixture and incorporation of oxides in the structure of the material. The final product was finely ground, to be used in the process of water depollution, in its powder form. The material obtained, of a reddish-brown colour, comes in the form of micron-sized fibres functionalized with metal oxides. The metallic oxides can be observed in the form of agglomerations of micron and nanometric dimensions [22-28].

For the morpho-structural investigations, a SEM Vega II LMU scanning electron microscope was used, coupled with an energy dispersive X-ray spectroscopy unit (EDX). Figure 1 (a, b, c) shows the structure of the material, at magnifications of 200x up to $3 \mathrm{kx}$. Figure 2 shows a map of the distribution of the chemical elements found in the structure of the material (a), the emission spectrum in the X-ray field emitted by the sample (b) and the percentage mass concentration of the chemical elements in the sample (c). The main elements of the structure of metallic oxides that have adsorption properties are presented in Figure 3. From the investigations, a relatively homogeneous distribution on the surface of the material can be observed. 


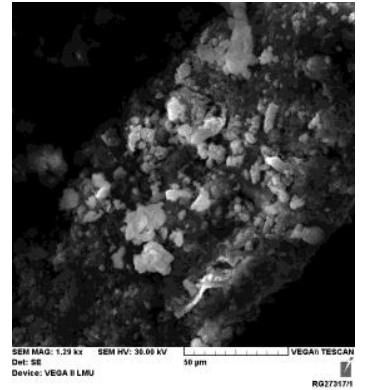

b.

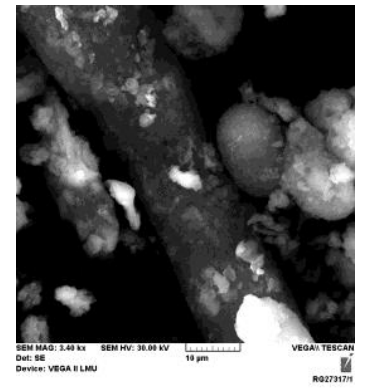

c.

Fig.1. SEM investigations of the material obtained

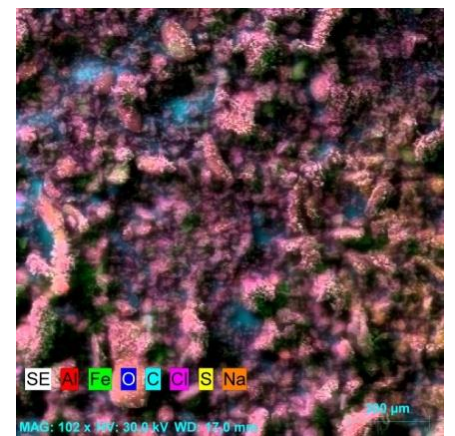

a.

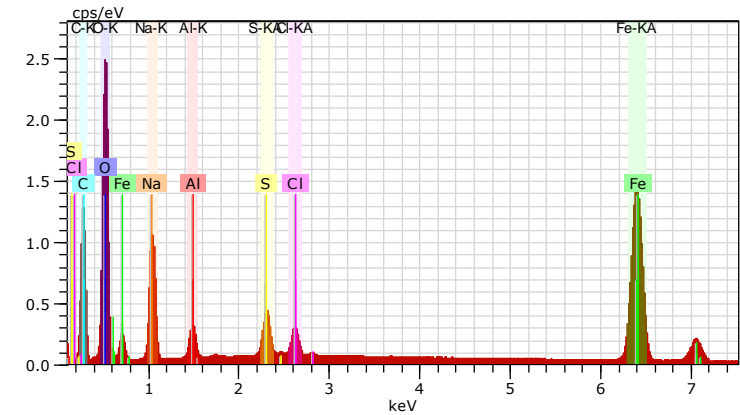

b.

\begin{tabular}{|l|l|}
\hline Ele & $\mathrm{W}$ \\
\hline $\mathrm{C}$ & 9. \\
\hline $\mathrm{O}$ & 52 \\
\hline $\mathrm{Na}$ & 15 \\
\hline $\mathrm{Al}$ & 2. \\
\hline $\mathrm{S}$ & 1. \\
\hline $\mathrm{Cl}$ & 1. \\
\hline $\mathrm{Fe}$ & 17 \\
\hline \multicolumn{2}{|l}{} \\
\hline
\end{tabular}

c.

Figure 2. (a) Map of chemical elements distribution in the sample; (b) X-ray emission spectrum; (c) The percentage mass concentration of the chemical elements in the sample

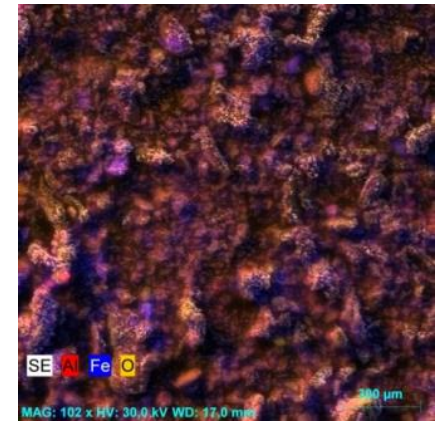

a.

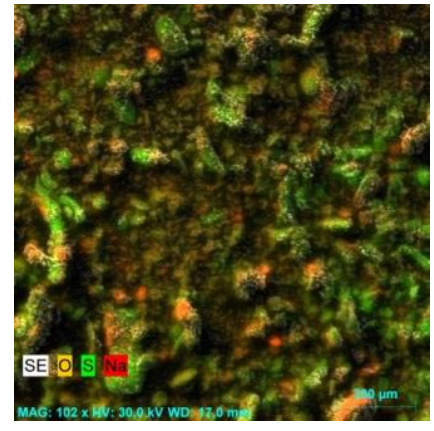

b.

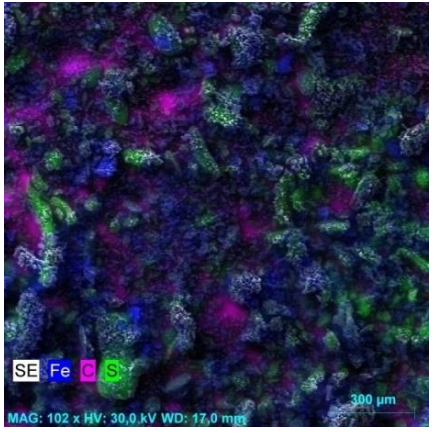

c.

Figure 3. Distribution of chemical elements in the sample. (a) the distribution of the oxides of $\mathrm{Al}$ and $\mathrm{Fe}$; (b) of the oxides / hydroxides of $\mathrm{S}$ and $\mathrm{Na}$; (c) of $\mathrm{S}, \mathrm{Fe}$ and $\mathrm{C}$ is shown on surface of the material

To test the efficiency of the material, a batch of water from the technological flow of the leather manufacturing (the leather and footwear industry) was used. All tests were performed at a temperature of $20-24{ }^{\circ} \mathrm{C}$ and a humidity of $52 \%$. Water from the leather manufacturing industry was selected because the market of the leather industry, on a global level, increases directly proportional with the urbanization of the countries and the population growth, making feasible the development of technologies for wastewater treatment specific to this industry, in present and in the near future.

In order to have a correct overview of the adsorbent material behaviour and of the pollutants existing in the technological water [29,30], 10 experimental works were performed, where a general working template was respected but whose parameters were modified at each test, in order to obtain as 
conclusive results as possible. The $\mathrm{pH}$ trigger is defined as the value of the $\mathrm{pH}$ to which the compounds from the wastewater and the functions of the adsorbent material react. The value of the $\mathrm{pH}$ trigger is adjusted to different values in order to establish the optimum reaction $\mathrm{pH}$.

\section{Method}

$0.25 \mathrm{~g}$ of composite material were added in $1 \mathrm{~L}$ of wastewater (Figure $4 \mathrm{a}$ ). The $\mathrm{pH}$ trigger was adjusted to values between 2 to $10.98 \% \mathrm{H}_{2} \mathrm{SO}_{4}$ was used for acidification and $2.2 \% \mathrm{CaO}$ for alkalizing the solution. After adjusting the $\mathrm{pH}, 30 \% \mathrm{H}_{2} \mathrm{O}_{2}$ was added in 5:2 ratio $\left(5\right.$ parts $\mathrm{H}_{2} \mathrm{SO}_{4}$ or $\mathrm{CaO}$ and 2 parts $\mathrm{H}_{2} \mathrm{O}_{2}$ ) (Figure $4 \mathrm{~b}$ ). $\mathrm{CaO}$ and $\mathrm{NaOH}$ were added in a ratio of 5:2 until the $\mathrm{pH}$ was adjusted to neutral. The mixture was matured for 30 minutes, and then filtered in the gravitational field, using several filter papers with medium porosity. The filtering speed depends on the size of the particles in the mixture. After completion of this phase, the solid residue was collected, dried at $60{ }^{\circ} \mathrm{C}$ and characterized by SEM / EDX investigations. The aqueous phase resulting after filtration was carbonated with $\mathrm{H}_{2} \mathrm{CO}_{3}$, and then the $\mathrm{pH}$ was adjusted with $\mathrm{CaO}$ and $\mathrm{NaOH}$, in a ratio of 5:2. $\mathrm{FeCl}_{3}$ was added to the mixture and then the $\mathrm{pH}$ was adjusted to neutral (Figure 4c). The mixture was filtered in the gravitational field, using several fine porosity filter papers. $\mathrm{AlCl}_{3}$ was added for clarifying, and then filtered in the gravitational field. The resulting water (Figure 4d) was characterized by the following parameters: extractable organic substances with organic solvents investigated by GC/MS, alkalinity - basicity, biochemical oxygen consumption in water - $\mathrm{CBO}$, chemical oxygen consumption in water - $\mathrm{CCO} \mathrm{Cr}$, total suspended matter, ammonium nitrogen, chlorides and phosphates.

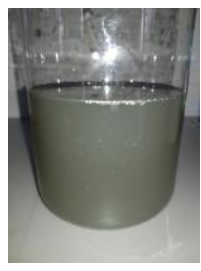

a.

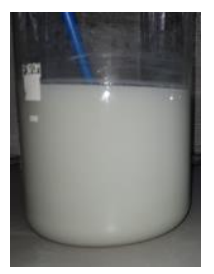

b.

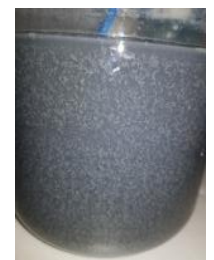

c.

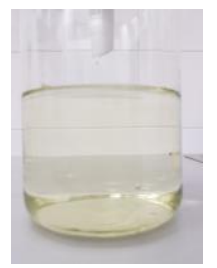

d.

Figure 4. Intermediate stages of the experimental work no. $3(\mathrm{pH}$ of destruction $=3$ ): (a) Initial wastewater; (b) Addition of $\mathrm{H}_{2} \mathrm{O}_{2}$; (c) Addition of $\mathrm{FeCl}_{3}$ and $\mathrm{H}_{2} \mathrm{PO}_{4}$; (d) Resulted treated water

\section{Results and discussions}

SEM investigations were carried out of the waste material resulting from the first stage filter. The samples were coded from P1 to P10. It has been observed that the material is in granular, nonhomogeneously distributed form. Particle size at 100x magnifications is between 20 and $100 \mu \mathrm{m}$ on average, and at 2000x magnifications the presence of subdomains is observed, with an average particle size between 5 and $20 \mu \mathrm{m}$. The samples P9 and P10 are highlighted, with very small particle sizes, from 10-30 $\mu \mathrm{m}$ and $5 \mu \mathrm{m}$ drops to submicron dimensions, at 100x and 2000x magnifications, respectively. The size is equivalent to the size of the deposit flakes in the first filtration step.

The purpose of EDX investigations is to observe the chemical nature of the solid residue substrates and to determine the concentration of the chemical elements present in the substrate. The residue is composed mainly of C, O, Na, Al, Si, P, S, Mg, Cl, Ca, Cr, Fe (Figure 5). 
Concentration of elements $(\mathrm{O}, \mathrm{S}$, $\mathrm{Ca}$ ) depending on the $\mathrm{pH}$ trigger

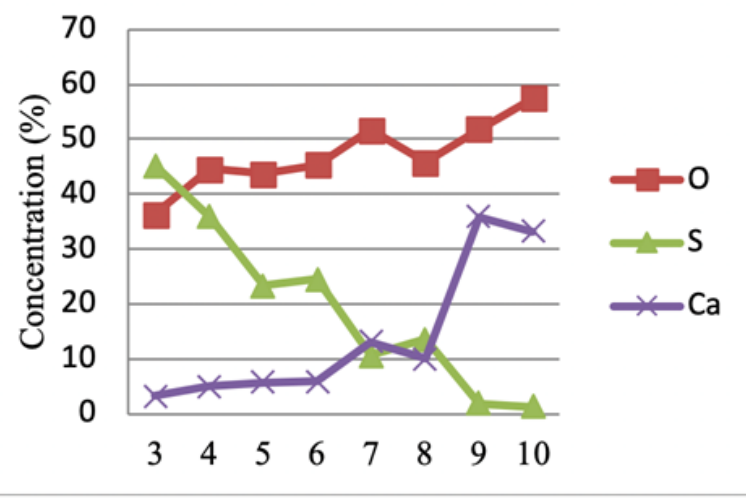

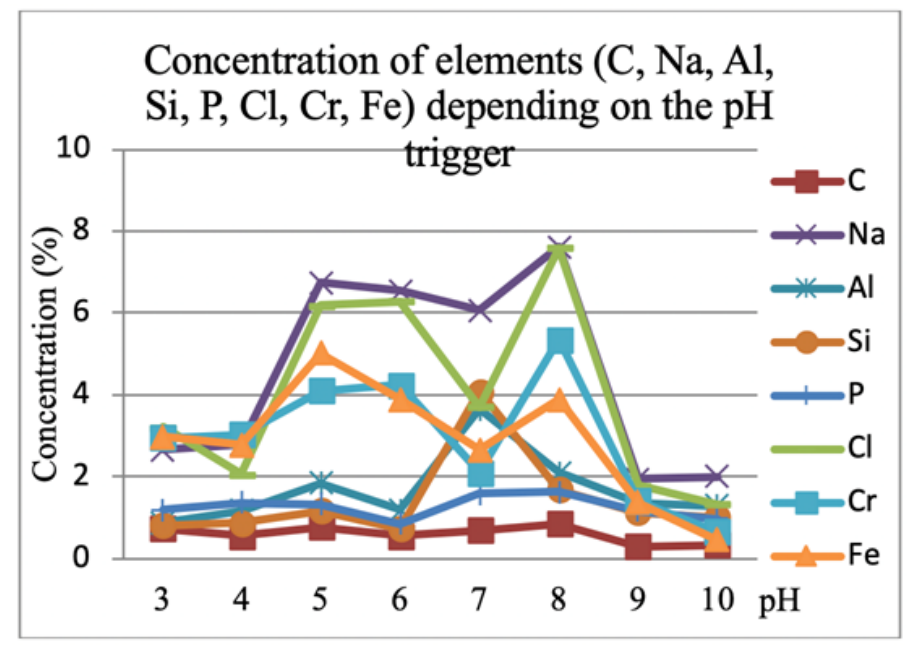

Concentration of elements (C, Na, Al,

Figure 5. Comparative analysis of the elements' concentration in solid residues vs. $\mathrm{pH}$

Oxygen is found in the percentage of $36.28 \%$ to $57.4 \%$ and has a tendency of growth directly proportional to the increase of the $\mathrm{pH}$ trigger value. The high oxygen concentration leads to the idea of the existence of several types of oxides and hydroxides in the structure of the residue, such as oxides of $\mathrm{Al}, \mathrm{Fe}, \mathrm{Ca}, \mathrm{Mg}, \mathrm{Cr}$, hydroxides of $\mathrm{Na}$ and $\mathrm{Ca}$. Sulphur is found in a percentage of $45.13 \%$ in $\mathrm{P} 3$, decreasing proportionally with the increase in the $\mathrm{pH}$ trigger, dropping to $1.3 \%$ in $\mathrm{P} 10$. The high concentration found in the samples with the low $\mathrm{pH}$ trigger value can be attributed to the use of $\mathrm{H}_{2} \mathrm{SO}_{4}$ for acidification. Calcium is the third most abundant element present in the solid residue, its variation being inversely proportional to that of sulphur. Calcium is found in concentrations of $3.14 \%$ in P3, rising to $35.84 \%$ in $\mathrm{P} 9$. The high concentration found in the samples with the high $\mathrm{pH}$ trigger value can be attributed to the use of $\mathrm{CaO}$ for water alkalization.

Elements such as $\mathrm{Al}, \mathrm{Fe}, \mathrm{S}, \mathrm{O}, \mathrm{Na}$ are also found in the structure of the adsorbent material used in the treatment. Additionally, $\mathrm{Ca}$ and $\mathrm{Na}$ were used in the first preparation step. Elements such as $\mathrm{Cr}, \mathrm{Cl}$, $\mathrm{Si}, \mathrm{Mg}$ come entirely from the composition of the waste water, also, variable concentrations of the other elements can come from the wastewater.

For GC / MS investigations, water samples were extracted in dichloromethane, followed by phase separation. The organic phase is dried over anhydrous sodium sulphate, filtered through a $0.45 \mu \mathrm{m}$ Sartorius and analysed by GC / MS. The aqueous phase was dried by centrifugation, eluted with 500 $\mu \mathrm{L} \mathrm{ACN}$ and then derivatized with $100 \mu \mathrm{L}$ BSTFA, at $60{ }^{\circ} \mathrm{C}$ for $30 \mathrm{~min}$. It is analysed by GC / MS. Because some of the organic compounds existing in the water samples cannot be completely extracted with an organic solvent, or some of them have an affinity for the aqueous environment, as well as the possibility of incompatible compounds being analysed as such in GC / MS, both the organic extract and the aqueous phase dried and salinized were analysed. 25 compounds were identified, and for the quantitative analysis, the external standard method was used (Figure 6). 


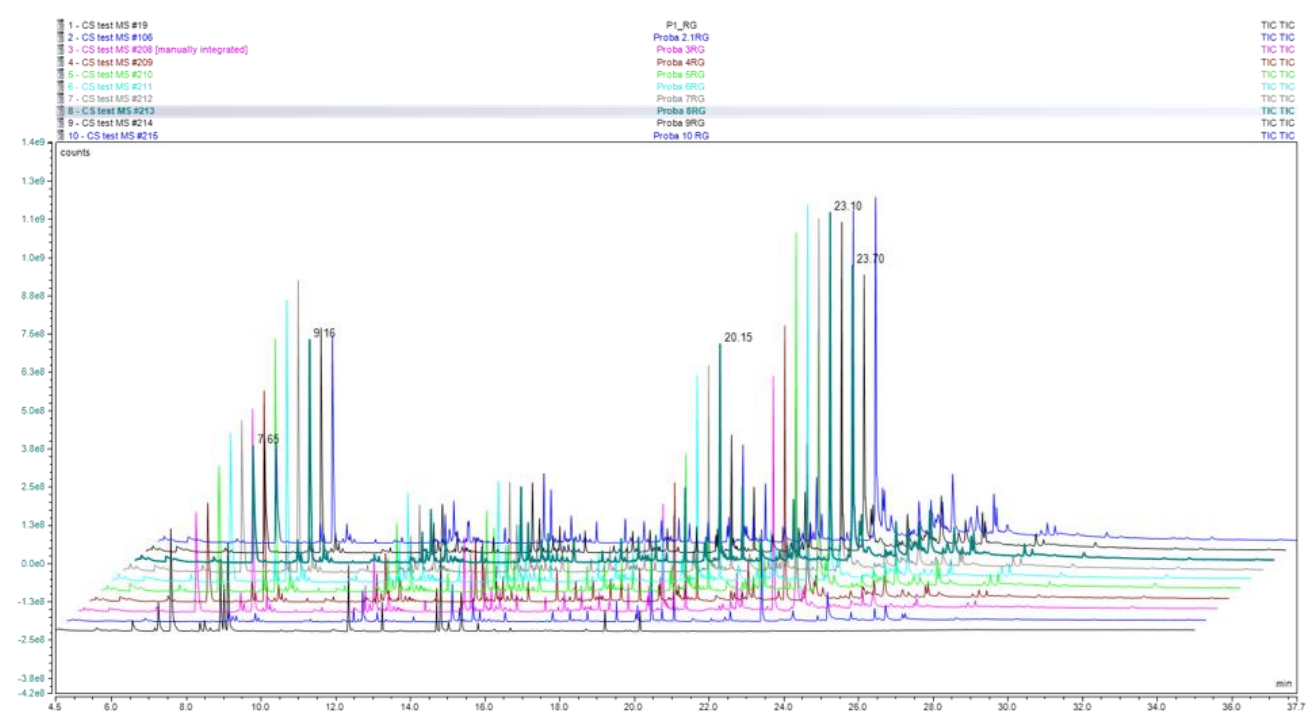

Figure 6. The organic extracts chromatograms

It is noted that samples prepared at a neutral or slightly acidic $\mathrm{pH}$ trigger $(\mathrm{P} 7-\mathrm{pH} 7$ and $\mathrm{P} 6-\mathrm{pH}$ 6) have a higher concentration of organic compounds present in the depolluted water. Improved results are observed, as the $\mathrm{pH}$ value is farther from neutral (both acidic and basic), with the observation that those prepared in acidic medium have slightly lower concentrations of organic compounds than those prepared in the basic medium. Concentrations of organic compounds have values between $8.3 \mathrm{ppm}$ and 0 (absence of compounds).

According to NTPA 002/2002 - The norm regarding the conditions of wastewater disposal in the sewage networks of the localities and directly in the sewage stations, the $\mathrm{pH}$ value of the depolluted water must be between 6.5-8.5 units of $\mathrm{pH}$. It was observed that the $\mathrm{pH}$ of the depolluted water samples is within the acceptance range of NTPA 002/2002, the values being between 7 and 8.1. It can be stated that the $\mathrm{pH}$ of the samples has a neutral character with slight alkaline tendencies.

\section{Biochemical oxygen demand}

Known as BOD5, it represents the amount of oxygen that is consumed for the oxidative degradation by the microorganisms of the contained organic substances, at a temperature of $20{ }^{\circ} \mathrm{C}$, for 5 days. According to NTPA 002/2002, the maximum admissible COD5 is $300 \mathrm{mg} / \mathrm{L}$. In figure 7, NTPA 002 maximum admissible value was $300 \mathrm{mg} / \mathrm{L}$, and measurement uncertainty was about $\pm 19.4 \%$. The BOD5 value of sample 0 exceeds the maximum allowed value by $205 \%$. A decrease in BOD5 value between 61.8-91.7\% of the value of the initial sample is observed. When analysing BOD5 values comparatively, it can be observed a tendency to improve the obtained results, as the $\mathrm{pH}$ trigger departs from the value of neutrality. The best results were obtained in samples P10 and P2. 


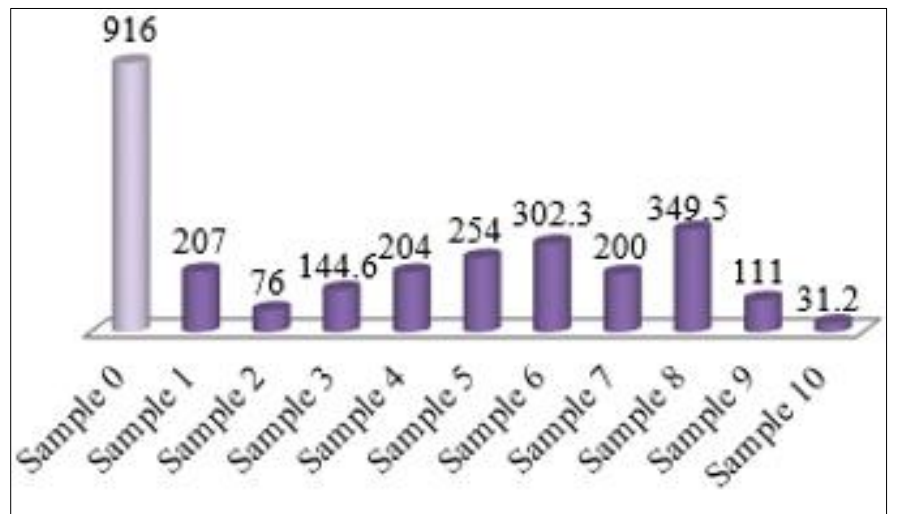

Figure 7. Comparative analysis of the value of BOD5 in water samples

\section{Chemical oxygen demand (potassium dichromate method)}

Noted COD-Cr, it represents the mass concentration of oxygen equivalent to the amount of potassium dichromate consumed for acid oxidation of dissolved and suspended organic matter in water. According to NTPA 002/2002, the maximum permissible limit of COD-Cr is $500 \mathrm{mg} / \mathrm{L}$. In Figure 8, NTPA 002 maximum admissible value was $500 \mathrm{mg} / \mathrm{L}$, and measurement uncertainty of $\pm 7.0 \%$.

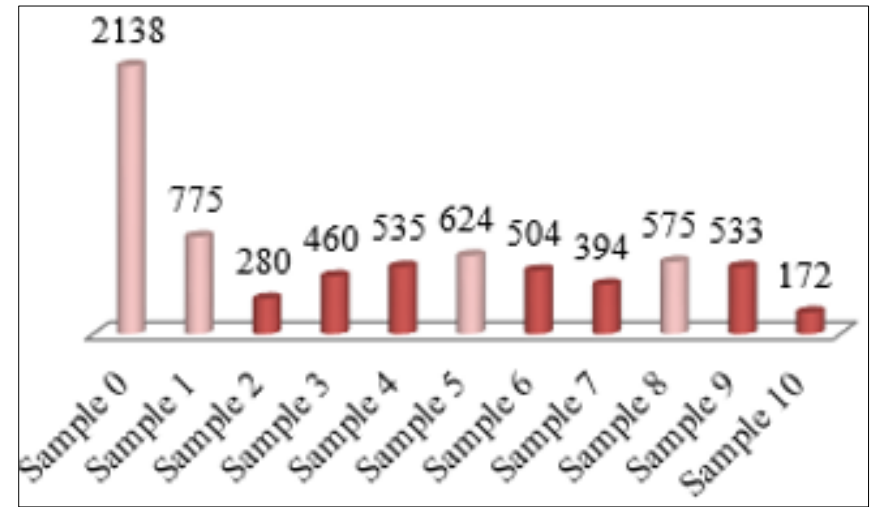

Figure 8. Comparative analysis of COD-Cr in water samples

The COD-Cr value of sample 0 exceeds the maximum allowed value by $327.6 \%$. There is a decrease in the COD-Cr value ranging from 70.8 to $91.9 \%$ of the value of the initial sample. The CCO$\mathrm{Cr}$ determinations were performed in accredited regime, with a measurement uncertainty of $7.0 \%$. Thus, it was found that 3 of the samples exceed the maximum allowed limit by $45 \%-\mathrm{P} 1,24.8 \%-\mathrm{P} 5$, $15 \%$ - P8. However, compared with the initial sample $\mathrm{P} 0$, the 3 samples show a decrease in $\mathrm{CCO}-\mathrm{Cr}$ value of $63.7 \%$ - P1, $70.8 \%$ - P5 and $73.1 \%$ - P8.

Comparatively evaluating sample 1 and sample 2 that were prepared at the same $p \mathrm{H}$ trigger, the difference being given by the ratio $\mathrm{H}_{2} \mathrm{SO}_{4}: \mathrm{H}_{2} \mathrm{O}_{2}$, a much better result is observed in sample 2 (ratio $5: 1)$. The P2 treatment had an efficiency of $23.2 \%$ better than in the case of P1, making sure that the COD-Cr value of P1 does not fall within the range allowed by NTPA 002. By evaluating the COD-Cr values in comparison, a tendency to improve the obtained results is observed, as the $\mathrm{pH}$ trigger is getting further from the value of neutrality. The best results were obtained in samples P10 and P2. 


\section{The total suspended materials (TSM)}

TSM represents water insoluble substances, which can be separated by filtration, centrifugation or sedimentation $(<2 \mathrm{~mm})$. The total solids, representing the suspended solids and the dissolved solids $(<1 \mu \mathrm{m})$, have important characteristics, which serve to establish the efficiency of the treatment process (Figure 9). According to NTPA 002/2002, the maximum permissible limit of TSM is $350 \mathrm{mg} / \mathrm{L}$.

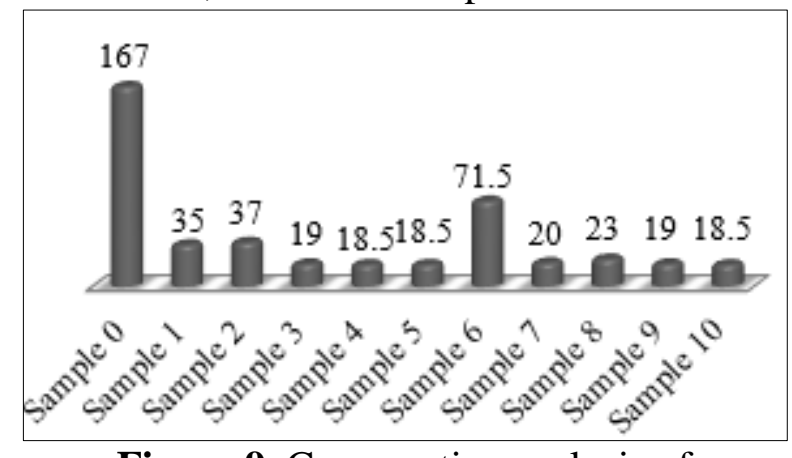

Figure 9. Comparative analysis of TSM in water samples

It is noted that all samples, including the initial sample, fall within the range allowed by NTPA 002/2002. However, compared to P0, there is a decrease in the TSM value ranging from $57.2 \%$ to 88.6 $\%$ from the initial sample value. Sample 6 shows the lowest treatment efficiency from the point of view of TSM, however, the value obtained is well below the maximum allowed limit. The other samples have very low TSM values.

\section{Ammonium nitrogen}

$\mathrm{NH}_{4}{ }^{+}$represents the nitrogen content of $\mathrm{NH}_{4}{ }^{+}$ions in the water. The ammonium nitrogen concentration of sample 0, exceeds the maximum allowed value by $2053 \%$. A decrease in the concentration of ammonium nitrogen by over $99.9 \%$ is observed for all samples (Figure 10).

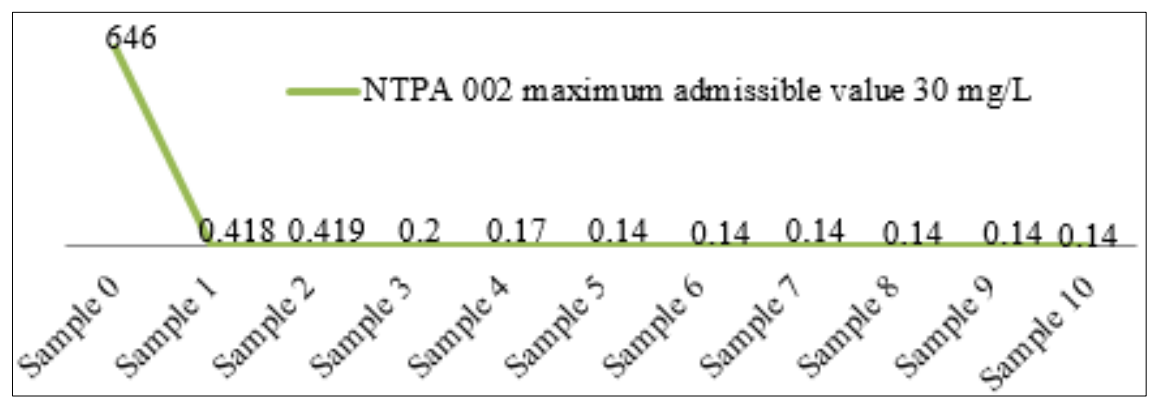

Figure 10. Comparative analysis of ammonium nitrogen concentration $(\mathrm{mg} / \mathrm{L})$ in water samples

\section{Conclusions}

The purpose of this paper consisted in obtaining new types of adsorbent materials doped with metallic oxides of micro and nanometric dimensions, with a role and applicability in the field of wastewater depollution and demonstrating their efficiency by testing on industrial wastewater. According to the results obtained after the material testing, we can conclude that the new adsorbent material has very good properties of adsorption for the pollutants present in the tested industrial wastewater. Also, it can be stated that the $p \mathrm{H}$ value of the reaction between the compounds from the wastewater and the adsorbent material is an essential factor in the water depollution process. Thus, 
from the present study it is observed that a $\mathrm{pH}$ farther from the neutral value gives a better efficiency. At the same time, the acidic values gave better results than the basic ones. Both the adsorbent material and the proposed treatment method allow further improvement and development.

\section{References}

1.SAMUEL, A.D., TIT, D.M., MELINTE (FRUNZULICA), C.E., IOVAN, C., PURZA, L., GITEA, M., BUNGAU, S., Rev. Chim., 68, (10), 2017, 2243.

2.SAMUEL, A.D., BREJEA, R., DOMUTA, C., BUNGAU, S., CENUSA, N., TIT, D.M., J. Environ. Prot. Ecol., 18, nr. 3, 2017, p. 871.

3.MIGUEL, N., ORMAD, M.P., MOSTEO, R., OVELLEIRO, J.L., Internat. J. Photoenergy, 7, 2012 , p. 1.

4.GITEA, M.A., BUNGAU, S., GITEA, D., PURZA, L., NEMETH, S., SAMUEL, A.D., BADEA, G., TIT, D.M., Rev. Chim., 69, (6), 2018, 1303.

5.BUNGAU, S., TIT, D.M., FODOR, K., CIOCA, G., AGOP, M., IOVAN, C., NISTOR CSEPPENTO, D.C., BUMBU, A., BUSTEA C., Sustainability, 10, nr. 8, 2018. https://doi.org/10.3390/su10082788

6.COJOCARU, A., BADEA, G.E., MAIOR, I., CRET, P., BADEA, T. Rev. Roum. Chim., 54, nr.1, 2009, p. 49.

7.BADEA, G.E., BADEA, T. Rev. Roum. Chim., 49, (7), 2004, 623.

8.PAHONTU, E., SOCEA, L.I., BARBUCEANU, S.F., ILIES, D.C., BADEA, M., OLARU, O.T., GULEA, A., SOCEA, B., BRATU, O., Rev. Chim., 69, (11), 2018, 2959.

9.RADA, E.C., ZATELli, C., CIOCA, L.I., TORRETTA, V., Sustainability, 10, 2018. doi:10.3390/su10010257

10.RADA, E.C., CIOCA L.I. Energy Procedia, 119, 2017, p. 72. https://doi.org/10.1016/ j.egypro. $\underline{2017.07 .050}$

11.PRIKRYL, R., OTRISAL, P., OBSEL, V., SVORC, L., KARKALIC, R., BUK, J. Nanomaterials, 8, 2018. doi: doi.org/10.3390/nano8090679.

12.OTRISAL, P., FLORUS, S., BARSAN, G., MOSTEANU, D. Rev. Chim., 69, (2), 2018, 300.

13.LAKATOS, E.S., CIOCA, L.I., DAN, V., CIOMOS, A.O, CRISAN, O.A, BARSAN, G., Sustainability, 10, 2018. doi:10.3390/su10030865

14.GIURGIU, L., BARSAN, G., MOSTEANU, D., The $9^{\text {th }}$ International Management Conference: Management and Innovation for Competitive Advantage, Bucharest, Romania, 2015, p. 506.

15.BUNGAU, C., BLAGA, F., GHERGHEA, C, International Conference on Production Research Regional Conference Africa, Europe and the Middle East (ICPR-AEM) / 3rd International Conference on Quality and Innovation in Engineering and Management (QIEM), Cluj Napoca, Romania, 2014, p. 55.

16.RASHED, I.G.A.A., AFIFY, H.A., AHMED, A.E.M., AYOUB, M.A.E.S., Desalin. Water Treat., 51, nr. 37-39, 2013. ttps://doi.org/10.1080/19443994.2013.792147

17.***https://www.reportlinker.com/p05027996/Global-Markets-and-Technologies-for-Water-

Recycling-and-Reuse.html, Global Markets and Technologies for Water Recycling and Reuse, 2017. Available at 30.06.2019

18.OTRISAL, P., FlORUS, S., SVORC, L., BARSAN, G., MOSTEANU, D. Mater. Plast., 54, (4), $2017,748$.

19.***https://www.bccresearch.com/market-research/ environment/global-markets-for-environmentalremediation-technologies.html, Global Markets for Environmental Remediation Technologies, 2017. Available at 30.06.2019

20.***https://unesdoc.unesco.org/ark:/48223/pf0000247153, The United Nations world water development report, 2017: Wastewater: the untapped resource, 2017. Available at 30.06.2019 
21.CAVAlU, S., BANICA, F., GRUIAN, C., VANEA, E., GOLLER, G., SIMON, V., J. Mol. Struct., 1040, 2013, p. 47.

22.CHARKHI, A., KAZEMEINI, M., AHMADI, S.J., KAZEMIAN, H. Powder Technol., 231, 2012, p. 1-6.

23.GUO, H., MA, F., FENG, X., LOU, X., TADE, M.O. Adv. Mat. Res. 610-613, 2013, p. 1242. https://doi.org/10.4028/www.scientific.net/AMR.610-613.1242

24.MA, G., GARBERS-CRAIG, A.M., Ironmak. Steelmak., 33, nr. 3, 2006, p. 229.

25.MARIAN, E., CAVALU, S., JURCA, T., BANICA, F., BRATU, I., Farmacia, 58, nr. 6, 2010, p. 749.

26.MARIAN, E., JURCA, T., BANICA, F., TITA, B., TITA, D., Rev. Chim., 59, (5), 495.

27.QU, X., ALVAREZ, P.J.J., LI, Q. Water Res. 47, 2013, p. 3931.

28.XU, P., ZENG, G.M, HUANG, D.L., FENG, C.L., HU, S., ZHAO, M. H., LAI, C., WEI, Z., HUANG, C., XIE, G. X., LIU, Z.F. Sci. Tot. Environ. 424, 2012.

29.ALI, I., ASIM, M., KHAN, T.A. J. Environ. Manag. 113, 2012, p. 170.

30.OTRISAL, P., MELICHARIK, Z., SVORC, L., BUNGAU, S., VIRCA I., BARSAN, G., MOSTEANU, D., Rev. Chim., 55, (4), 2018, 545.

$\overline{\text { Manuscript received: } 11.05 .2019}$ 